\title{
Fondos sociales obligatorios: la justificación de su irrepartibilidad en los orígenes del cooperativismo y del movimiento obrero organizado
}

\author{
(Mandatory social funds: \\ The justification of its undistribility in the origin \\ of the cooperative movement and the organized \\ labor movement) \\ Héctor Mata Diestro ${ }^{1}$ \\ Abogado (España)
}

Sumario: Introducción. I. Precedentes conceptuales en nuestra legislación cooperativa. II. Origen del cooperativismo moderno. 2.1. Contexto en el cual surge. 2.2. Primeras experiencias cooperativas. 2.3. El legado de Rochdale. 2.4. Trabajo cooperativo y emancipación obrera. Conclusiones. Fuentes documentales.

Summary: Introduction. I. Conceptual precedents in our cooperative legislation. II. Origin of the modern cooperative movement. 2.1. Context in which it appeared. 2.2. First cooperative experiences. 2.3. The legacy of Rochdale. 2.4. Cooperative work and worker emancipation. Conclusions. Documentary sources.

Resumen: La característica principal del Fondo de Reserva Obligatorio y del Fondo de Educación y Promoción es que no pueden repartirse entre los socios y socias cooperativistas. El presente trabajo de investigación centra su análisis en los precedentes legislativos existentes en relación a estos fondos sociales obligatorios, al tiempo que se van definiendo sus principales características, enlazándolo posteriormente con los orígenes del cooperativismo moderno y del propio movimiento obrero organizado, como método explicativo para la justificación de su irrepartibilidad.

Palabras clave: fondos sociales, irrepartibilidad, cooperativismo, sindicalismo.

1 Email: hector@primerodemayo.coop 
Abstract: The main characteristic of the Mandatory Reserve Fund and the Education and Promotion Fund is that they can not be distributed among cooperative members. Present research work analysis is focused on existing legislative precedents in relation to these mandatory social funds, while defining its main characteristics. Later, it is linked with the origin of the modern cooperative movement and the organized labor movement itself to explain the justification of its undistribility.

Keywords: social funds, undistribility, cooperative movement, unionism. 


\section{Introducción}

El Fondo de Reserva Obligatorio es aquel que tiene como finalidad la consolidación, el desarrollo y la garantía de la sociedad cooperativa. Por su parte, el Fondo de Educación y Promoción es aquel destinado a actividades de promoción cooperativa, formación de personas asociadas y trabajadoras, así como a acciones sociales.

En los precedentes de nuestra legislación cooperativa, podemos hallar las notas definitorias de estos fondos sociales obligatorios. Cuya característica principal es que no pueden repartirse entre los socios y socias cooperativistas. Irrepartibilidad que enlaza con la génesis del cooperativismo moderno y el resto del movimiento obrero organizado.

El vínculo entre el movimiento cooperativo y el asociacionismo obrero, el cual se desarrollará a lo largo del presente estudio, explica por ejemplo, la aprobación de la primera Ley de Cooperativas en nuestra tradición legislativa.

\section{Precedentes conceptuales en nuestra legislación cooperativa}

La primera Ley de Cooperativas estatal se dictó en forma de Decreto el 4 de julio de 19312, que fue confirmado y elevado al rango de Ley el 9 de septiembre de ese mismo año ${ }^{3}$. Motivo por el cual, se considera a la II República como el origen del cooperativismo regulado en el Estado español. Lo que sirvió además, de modelo a leyes de otros países, especialmente de Latinoamérica ${ }^{4}$.

Del mismo modo, la Ley de Cooperativas de 1931 contiene la que constituye la primera referencia a la palabra «fondo» en nuestra tradición legislativa cooperativa. Concretamente, al Fondo de Reserva Obligatorio, denominado "fondo de reserva irrepartible». Al que las cooperativas debían destinar un porcentaje de los excedentes y una serie de cantidades, para poder obtener la calificación de «cooperativas popula-

2 Decreto de 4 de julio de 1931, determinando lo que ha de entenderse por Sociedad Cooperativa y fijando sus condiciones legales, publicado en la Gaceta de Madrid, n. ${ }^{\circ} 188$, de 7 de julio de 1931.

3 Ley de 9 de septiembre de 1931, declarando Leyes de la República los Decretos que se insertan, publicada en la Gaceta de Madrid, n. ${ }^{\circ}$ 253, de 10 de septiembre de 1931

4 MORALES GUTIÉRREZ, Alfonso Carlos. "La democracia industrial en España: orígenes y desarrollo de las empresas de trabajo asociado en el siglo XX». CIRIEC-España, Revista de Economía Pública, Social y Cooperativa, n. ${ }^{\circ} 44,2003$, pág. 144. 
res», pasando a disfrutar de una serie de exenciones, facultades y beneficios de diversa índole.

En el caso concreto de las "Cooperativas de trabajadores», el artículo 95 del Reglamento para la aplicación de la Ley de Cooperativas, aprobado por Decreto el 2 de octubre de $1931^{5}$, al tiempo que recogía una referencia implícita al Fondo de Educación y Promoción, exigía:

Que los rendimientos líquidos de cada ejercicio se destinen, cuando menos en un 50 por 100, a la constitución y aumento de un fondo de reserva irrepartible y al sostenimiento de obras sociales que figuren en la lista de las oficialmente aprobadas, siendo, por lo menos, un 15 por 100 de los rendimientos del ejercicio lo destinado a cada una de las dos aplicaciones indicadas.

La legislación cooperativista republicana, emanada del más clásico ideario cooperativista, tal y como señala CHAVES ÁVILA ${ }^{6}$, pretendió desarrollar las diferentes corrientes cooperativas existentes, con especial atención a la «católica» y a la "obrera socialista». Siendo el movimiento encuadrado en esta última, el que mayor impulso imprimiría al cooperativismo durante la Republica, particularmente en el contexto de economía de guerra; en sus dos vertientes, la «ugetista» y la «libertaria». Lo que, en opinión del autor, explicará su depuración posterior durante la dictadura franquista, a diferencia de la primera.

En lo que al Fondo de Educación y Promoción se refiere, si bien no se recogía como tal en la Ley de Cooperativas de 1931, sí que se establecía la obligación de destinar anualmente una parte de los excedentes, a una o varias de las obras sociales que aparecían en una relación confeccionada al efecto por el Ministerio de Trabajo, tal y como hemos visto en el ejemplo de las "Cooperativas de trabajadores». Algo que el Reglamento para la aplicación de la Ley de Cooperativas de 1931 también exigía, al tiempo que destinar una serie de rendimientos al Fondo de Reserva, a las "Cooperativas de consumidores» (Art. 85) y «Cooperativas de crédito» (Art. 98) que quisieran tener la consideración de «populares». Condición que, previo informe favorable del Consejo de Trabajo, se extendía igualmente a otras Cooperativas no profesionales que tuvieran consignada estatutariamente «la declaración de estar pri-

5 Decreto de 2 de octubre de 1931, aprobando el Reglamento para la aplicación de la ley de Cooperativas, publicado en la Gaceta de Madrid, n. ${ }^{\circ} 294$, de 21 de octubre de 1931

6 CHAVES ÁVILA, Rafael. "Las cooperativas en la Segunda República Española. 1931, primera Ley Española de Cooperativa». Noticias del CIDEC, n. ${ }^{\circ} 33,2001$, págs. 82-84. 
mordialmente constituidas para mejorar la condición económica y social de obreros y personas de medios modestos en general» (art. 101). Para ser reconocida directamente a las "Cooperativas escolares» (art. 107), que era una variedad de Cooperativa de consumo, que tenía como objeto principal el suministro a las personas asociadas de material de estudio y artículos de consumo o de uso personal; pero que podía practicar a pequeña escala todas las formas de cooperación a su alcance, así como organizar cualquier obra social complementaria.

La Ley de Cooperación de 2 de enero de 19427, será la primera en utilizar la expresión "fondo» para sendos fondos «irrepartibles», denominados concretamente «fondo de reserva» y «fondo de obras sociales»; algo que desde entonces será una constante en la legislación cooperativa. Al año siguiente, se aprobaría el Reglamento para la aplicación de la Ley de Cooperación de 2 de enero de $1942^{8}$, con varios artículos dedicados a los "fondos de reserva y obras sociales», el cual fue posteriormente rectificado 9 .

Posteriormente, la Ley General de Cooperativas de 198710, utilizará la expresión «fondos comunitarios» para referirse a ambos, en la propia definición de cooperativa de su artículo primero. Lo que ha sido interpretado como referencia a una cualidad de servicio a la Comunidad, esto es, al entorno local donde se desenvuelve la cooperativa o a la sociedad en general ${ }^{11}$.

Asimismo, en la definición de cooperativa del citado artículo primero, se incluía otra característica común a ambas instituciones, que alude a cómo se originan.

Llegados a este punto, podemos decir que, las cantidades que conforman ambos fondos, se descuentan de los resultados, siempre y cuando el balance de la cooperativa arroje beneficios, reduciendo así la

7 Ley de 2 de enero de 1942, de cooperación, publicada en el Boletín Oficial del Estado, n. ${ }^{\circ} 12$, de 12 de enero de 1942.

8 Decreto de 11 de noviembre de 1943, aprobando el Reglamento para la ejecución de la Ley de Cooperativas de 2 de enero de 1942, publicado en el Boletín Oficial del Estado, n. ${ }^{\circ} 55$, de 24 de febrero de 1944.

9 Orden de 10 de marzo de 1944, por la que se dispone se publiquen nuevamente en el Boletín Oficial del Estado los artículos del Reglamento para la aplicación de la Ley de Cooperación, inserto en dicho Boletín de 24 de febrero último, debidamente rectificados, publicada en el Boletín Oficial del Estado, n. ${ }^{\circ}$ 76, de 16 de marzo de 1944.

10 Ley 3/1987, de 2 de abril, General de Cooperativas, publicada en el Boletín Oficial del Estado, n. ${ }^{\circ} 84$, de 8 de abril de 1987.

11 ELENA DÍAZ, Fernando. «El Fondo de Reserva obligatorio en la nueva Ley General de Cooperativas». REVESCO Revista de Estudios Cooperativos, n. ${ }^{\circ}$ 56-57, 1988-1989, pág. 51. 
parte de éstos a repartir entre las personas asociadas. Lo que en definitiva, implica que tales cantidades sean socializadas.

Para concluir, señalar que el artículo 94.2 de la Ley General de Cooperativas del $1987^{12}$, vuelve a citarlos conjuntamente y además de "obligatorios» los califica de "sociales», en referencia a que son propiedad de la sociedad, algo que también tienen en común ambos fondos.

La existencia de estos fondos, con unas características como las descritas, forma parte del ADN de las sociedades cooperativas. Como demuestra, por ejemplo, su inclusión en la definición de cooperativa del artículo primero de la Ley del 87. Y su irrepartibilidad, como desarrollaré a continuación, procede de una tradición que enlaza con las fundadoras y fundadores de las primeras cooperativas.

\section{Origen del cooperativismo moderno}

\subsection{Contexto en el cual surge}

El cooperativismo moderno, tal y como lo conocemos hoy en día, nació en el contexto de la Revolución Industrial, que tuvo lugar a partir de la segunda mitad del siglo XVIII en Inglaterra y después del segundo cuarto del siglo XIX se extendió al resto de la Europa occidental y los Estados Unidos.

La industrialización supuso la generalización de una situación de terrible miseria y explotación, configurando unas condiciones de trabajo y de vida para hombres, mujeres y menores, que, en conjunto, determinan el carácter socialmente catastrófico de dicho periodo.

El profesor THOMPSON ${ }^{13}$ afirma que «el obrero «medio» permanecía muy cerca del nivel de subsistencia». Que en las ciudades industriales, "los problemas de suministro de agua, saneamiento, superpoblación y de la utilización de viviendas para actividades industriales se multiplicaban», facilitando la propagación de epidemias. Así como que, en las zonas industriales, la mortalidad infantil y de las mujeres durante

12 Artículo 94.2: Las Sociedades Cooperativas que se fusionen en una nueva o que sean absorbidas por otra ya existente quedarán disueltas, aunque no entrarán en liquidación, y sus patrimonios, socios y, en su caso, los asociados pasarán a la Sociedad nueva o absorbente, que asumirá los derechos y obligaciones de las Sociedades disueltas. Los Fondos Sociales, obligatorios o voluntarios, de las Sociedades disueltas pasarán a integrarse en los de la Sociedad Cooperativa nueva o absorbente.

13 THOMPSON, Edward Palmer. La formación de la clase obrera en Inglaterra. Capitán Swing, Madrid, 2012, págs. 292-455. 
el parto aumentó, y «la vida se volvió más corta y más difícil». Especialmente para las madres asalariadas, a quienes les tocó la peor parte, «tanto del mundo doméstico como del industrial».

Un «infierno en la tierra» con origen en la época industrial, que ENGELS ${ }^{14}$ documentaría ampliamente en su obra La situación de la clase obrera en Inglaterra.

Esto explica, en palabras de MERINO HERNÁDEZ ${ }^{15}$, que el cooperativismo naciera «en la misma época en la que también se concretaron el sindicalismo y el socialismo, impulsado por la misma concepción de vida, y siempre en la búsqueda de soluciones superadoras de la situación existente para la clase obrera». Compartiendo por ello, desde su origen, «una misma identidad».

De hecho, la «cooperación» fue concebida en esa época por ROBERT OWEN, considerado uno de los máximos representantes del socialismo utópico o premarxista, como un sinónimo de "socialismo» ${ }^{16}$. Cuestión que será ampliamente desarrollada por LAMBERT ${ }^{17}$ en su libro La doctrina cooperativa:

La misma palabra «socialismo» en el sentido de doctrina económica, se utilizó por primera vez en Inglaterra en 1821-22 en la correspondencia de Robert Owen y sus amigos, y después en 1833, en un artículo del periódico «The poor man's Guardian» («El guardián del hombre pobre»). El índice de la colección del «New Moral World» del 20 de febrero de 1836 decía: «Socialism: alias Owenism». El socialismo es, pues, en su origen, sinónimo de owenismo, la doctrina del padre de la cooperación integral.

Es más, en la «nebulosa inicial» del movimiento obrero, puede decirse, siguiendo a LASSERRE ${ }^{18}$, que «muchas de las primeras asociaciones obreras eran a la vez, más o menos, mutualidad, sindicato, partido y cooperativa». Definiéndose y estructurándose posteriormente, «por diferenciación creciente», las principales ramas del asociacionismo obrero, esto es: el sindicalismo, el socialismo político y el cooperativismo.

14 ENGELS, Friedrich. La situación de la clase obrera en Inglaterra. Akal Editor, Madrid, 1976, pág. 86.

15 MERINO HERNÁNDEZ, Santiago. "Los orígenes del cooperativismo moderno y el socialismo premarxista». GEZKI, n.1, 2005, pág. 175.

16 LICHTHEIM, George. Breve historia del socialismo. Alianza Editorial, Madrid, 1970, págs. 56-57.

17 LAMBERT, Paul. La doctrina cooperativa. Intercoop Editora Cooperativa Limitada, Buenos Aires, 1970, p. 31.

18 LASSERRE, George. El cooperativismo. Oikos-tau S.A., Barcelona, 1972, págs. 10-11. 


\subsection{Primeras experiencias cooperativas}

El 14 de marzo de 1761, en la ciudad de Fenwick, situada en la región escocesa de East Ayrshire, quince tejedoras se reunieron en la iglesia local y firmaron una carta constitutiva de la primera cooperativa de consumo de la que existen registros completos. Si bien el propósito inicial de la «Sociedad de las Hilanderas de Fenwick» o "Fenwick Weavers' Society» fue mejorar las condiciones de vida de sus integrantes, su actividad pronto incluyó la concesión de préstamos a sus miembros y familias, así como la compra de alimentos a granel para ser vendidos a bajo coste a la comunidad local. En sus estatutos, incluyeron una serie de principios sobre cómo debía funcionar la nueva sociedad, a saber: honestidad, fidelidad entre sus miembros, toma de decisiones por la mayoría, precio justo en la venta de productos, contribución a un fondo contra la pobreza y aportación de cada miembro de 2 chelines y 6 peniques ${ }^{19}$.

Las pioneras de Fenwick también demostraron su interés por la comunidad, a través de la compra de libros y más tarde, con la creación de una biblioteca para la ciudad en 1808. En el preámbulo de cuya normativa, hicieron constar su compromiso con la difusión cultural:

Todo aquello que tienda a mejorar la condición de la persona, reclama su cordial consideración. Para este fin, nada hay más conveniente que una biblioteca adaptada a los hábitos y actividades diversas de la comunidad donde esté establecida. En Escocia, la utilidad de tales instituciones ha sido felizmente reconocida desde hace mucho tiempo; estando en deuda con la difusión del conocimiento, de la cual han sido un considerable instrumento, bajo Dios, por gran parte de la iluminación y libertad que hoy disfrutamos ${ }^{20}$.

Lo que ya en origen, muestra un claro vínculo entre la sociedad cooperativa y la organización de actividades en beneficio del entorno local o de la comunidad en general, con especial atención a la educación popular.

19 MCDONNELL, Diarmuid; MACKNIGHT, Elisabeth y DONNELLY, Hugh. "Case Study 1.4. The Fenwick Weavers». Reseña de The Co-operators - A History of the Fenwick Weavers, de John McFadzean. En Democratic Enterprise: Ethical business for the 21st century. Co-operative Education Trust Scotland, Escocia, 2012.

20 CRAWFORD, John. "The community library in Scottish history». IFLA Journal, vol. 28, n. ${ }^{\circ}$ 5-6, 2002, pág. 252. 
En ese mismo periodo, COLE21 relata cómo, obreros empleados por el gobierno en los astilleros ingleses de Woolwich y Chatham, fundaron cooperativas para la producción y distribución de harina de maíz, en contra de los altos precios cobrados por quienes tenían el monopolio local. Estas primeras sociedades rápidamente entraron en conflicto con los panaderos privados, así como con los molineros; y cuando, en 1760, se quemó el molino de Woolwich, los panaderos locales fueron acusados de incendio premeditado. Lo que hizo que los trabajadores se organizaran, tanto en Woolwich como en Chatham, para garantizar la seguridad de su molino.

Aparecen en Escocia nuevas sociedades fundadas por trabajadores y trabajadoras textiles de Goran (1777) y Darvel (1840)22. Mientras que en la temprana fecha de 1819, obreros ingleses de la industria tabacalera, después de once semanas de huelga, comenzaron a organizar ellos mismos la producción por su propia cuenta ${ }^{23}$.

En 1795, cuenta FOTHERGILL ROBINSON24, los «habitantes pobres» de un pueblo en el condado de Yorkshire, fundaron la «Hull Anti-Mill Society» con el objetivo de construir un molino para el abastecimiento de harina, mediante suscripciones semanales de sus miembros. El éxito del «Molino Harinero de Hull» permitió que del año 1800 en adelante, surgieran otros molinos en similares circunstancias. Estas experiencias cooperativas en Hull, Whitby, Sheerness y Devonport, resultaron competentes desde el punto de vista económico, según destaca la autora; cambiando el viejo modo de producción en los establecimientos molineros y permitiendo suministrar a la comunidad un producto puro a precios razonables.

Dentro de estas primeras experiencias, MAYO ${ }^{25}$ destaca la «Cooperativa de obreros sastres de Birmingham», que fue creada en 1777. Al igual que ocurriría con los «carpinteros de Filadelfia» catorce años después, cuenta, los sastres se declararon en huelga. En este caso, protestaban porque se estaba tratando de imponer un cambio en la manera de retribuir su trabajo, pasando de una tasa diaria a un pago por ar-

21 COLE, George Douglas Howard. A century of cooperation. The Cooperative Union Limited, Londres, págs. 13 y 14.

22 MERINO HERNÁNDEZ, Santiago. "Los orígenes del cooperativismo moderno y el socialismo premarxista». Op. cit., pág. 176.

23 THOMPSON, Edward Palmer. La formación de la clase obrera en Inglaterra. Op. cit., p. 842.

${ }_{24}$ FOTHERGILL ROBINSON, Margaret. The Spirit of Association, being some account of the gilds, friendly societies, co-operative movement, and trade unions of Great Britain. John Murray, Londres, 1913, pág. 191.

25 MAYO, Ed. Breve historia de la cooperación y la mutualidad. Co-operatives UK, Manchester, 2017, pág. 34. 
tículo, esto es, por pieza de trabajo. La empresa cooperativa sirvió para vender su producción mientras estuvieron en huelga.

Ya en 1820, un grupo de «impresores de Londres» formaron una sociedad cooperativa que al año siguiente comenzó a imprimir el que sería el primer diario de inspiración owenista, The Economist ${ }^{26}$.

Respecto a la educación, THOMPSON ${ }^{27}$ refiere «relatos sobre tejedores de aldeas aisladas que enseñaban geometría dibujando con tiza sobre las losas del suelo». Del mismo modo que, en Spitalfields, "los tejedores de seda daban apoyo a sociedades de matemáticas, historia, floricultura, entomología, recitación y música». Recordando también a «gran cantidad de pañeros con pequeños talleres» que trajeron consigo logros educativos y pequeñas bibliotecas.

ENGELS28 referirá por entonces, como "diversas secciones de obreros» habían «fundado por propia iniciativa gran número de escuelas y salas de lectura, con el objetivo de elevar la educación intelectual».

En 1834, cuatro obreros parisinos fundaron una de las primeras cooperativas de producción, denominada «Association chrétienne des Bijoutiers en doré», que, a pesar de un comienzo modesto, dio buenos resultados; llegando a tener hasta ocho sucursales en todo París y manteniéndose hasta $1873^{29}$.

En Barcelona, alrededor de un centenar de familias trabajadoras crean en 1840 una cooperativa de consumo, la "Compañía Fabril de Tejedores del Algodón de Barcelona», iniciando una larga experiencia que continuaría con la cooperativa de consumo de la «Fraternitat de la Barceloneta», y luego, en 1880, con la cooperativa de producción de los «Silleros» 30 .

Aun sin obviar otros focos en Valencia, Madrid y Andalucía, el epicentro del primer cooperativismo peninsular se situó en Cataluña. El hecho de que estas primeras experiencias cooperativas, junto al derecho de asociación, carecieran de reconocimiento legal, obligaba a las trabajadoras y trabajadores a asociarse en la clandestinidad ${ }^{31}$.

26 KOLMERTEN, Carol A. Women in Utopia: The Ideology of Gender in the American Owenite Communities. Syracuse University Press, Nueva York, 1998, pág. 22.

27 THOMPSON, Edward Palmer. La formación de la clase obrera en Inglaterra. Op. cit., págs. 325-328.

28 ENGELS, Friedrich. La situación de la clase obrera en Inglaterra. Op. cit., pág. 272.

29 LASSERRE, George. El cooperativismo. Op. cit., pág. 11.

30 GIL DE SAN VICENTE, Iñaki. Cooperativismo obrero, consejismo y autogestión socialista. Algunas lecciones para Euskal Herria. Boltxe Liburuak, Bilbao, 2013, pág. 25.

31 ARRIETA, Leyre; BARANDIARAN, Miren; MUJIKA, Alazne y RODRÍGUEZ, José Antonio. El Movimiento Cooperativo en Euskadi 1884-1936. Fundación Sabino Arana Kultur Elkargoa, Bilbao, 1998, págs. 35-37. 
Estas y otras cooperativas supusieron la experiencia que luego sería recogida por los denominados «Pioneros de Rochdale» en sus estatutos, cuando en 1844, veintisiete trabajadores y una trabajadora de la industria textil en paro tras una huelga en demanda de mejoras salariales, crearon en un barrio pobre de Manchester, la cooperativa de la cual saldrían los conocidos como "Siete principios de Rochdale»; que desde ese momento, vertebrarían el espíritu del cooperativismo.

Entre los propósitos de la sociedad, estaba abrir un almacén para la venta de provisiones, ropa, etc.; comprar o construir un cierto número de casas destinadas a sus miembros; o fabricar los artículos que la sociedad estimare conveniente para proporcionar trabajo a sus integrantes; así como «organizar las fuerzas de la producción, de la distribución, de la educación y de su propio gobierno» 32 .

\subsection{El legado de Rochdale}

En palabras de la profesora ALONSO PEREZ ${ }^{33}$, «el socialismo utópico inglés tiene como máximo representante a Robert Owen y como logro importante la cooperativa de Rochdale», proyecto cooperativo "que reorganiza la actividad de consumo, de alojamiento, de educación, etc. en 1844 en la periferia de Manchester». El cual «procede de las ideas owenistas y participa del ímpetu obrero y de la toma de conciencia de un movimiento social que se lleva a cabo como respuesta a un fracaso en un conflicto laboral, y también participa de la experiencia de cooperativas anteriores» así como de «la práctica obrera, sin renunciar al anticapitalismo».

La "Sociedad Equitativa de los Pioneros de Rochdale» fue constituida gracias a las aportaciones de sus miembros y de una organización obrera, el «sindicato de tejedores». Y su éxito, permitió la extensión del cooperativismo a campos como: la previsión social («Rochdale Equitable Provident Sick and Burial Society»), la construcción de viviendas («Co-operative Building society»), los seguros («Co-operative Insurance Society»), o la educación; mediante la creación de una biblioteca, una escuela y la organización de «clases nocturnas en las que se enseñaba economía, política, matemáticas, francés» ${ }^{34}$.

32 HOLYOAKE, Georges Jacob. Historia de los Pioneros de Rochdale. Intercoop Editora Cooperativa Ltda, Buenos Aires, 1989, pág. 14.

33 ALONSO PÉREZ, Matilde. «El cooperativismo valenciano: Desde sus inicios hasta la Ley de 1974». CIRIEC-España, n. ${ }^{\circ} 11,1991$, págs. 60 y 61.

34 DROZ, Jacques (director). Historia general del socialismo. De los orígenes a 1875. Ediciones Destino S.A., Barcelona, 1984, Tomo II, págs. 753-756. 
Entre los principios organizativos legados al resto de cooperativas que la sucedieron, podemos encontrar el «compromiso social de la cooperativa», la «aspiración de cooperativizar la organización económica y social del mundo», o la «promoción de la educación entre los miembros» ${ }^{35}$.

Así, el 20 de agosto de 1849, narra HOLYOAKE ${ }^{36}$, había sido nombrado un comité «a fin de que estableciesen una sección para la venta de libros y de diarios. Las utilidades obtenidas debían ser empleadas en la adquisición de libros y útiles para la Sociedad». En cuanto al empleo de las utilidades de la cooperativa, el autor refiere como se estableció un 2,5 por ciento «para ser empleado con fines de educación general». Lo que calificara de «rasgo más característico del serio propósito de los cooperadores de trabajar por su perfeccionamiento intelectual». Constituyéndose de esta manera, "el fondo especial de educación para el desarrollo intelectual de los socios, para el sostén y fomento de la biblioteca y para cualquier otro medio de acción educacional» que se estimare conveniente.

Lo que muestra nuevamente un vínculo esencial entre la sociedad cooperativa, sus principios definidores y la promoción de actividades en solidaridad con la comunidad, tales como la educación.

Los denominados «Pioneros» establecieron también «un fondo de reserva formado por las cuotas de ingreso de un chelín, abonadas por los nuevos socios, y además por la retención de un chelín por acción que los socios deben dejar al retirar las dos últimas acciones» ${ }^{37}$.

\subsection{Trabajo cooperativo y emancipación obrera}

ROBERT OWEN fue el primer pensador socialista que promovió la unidad dentro del movimiento obrero. En busca de «una gran reagrupación de fuerzas obreras», vio la ocasión para el «establecimiento de un sistema socialista y cooperativo», proponiendo en 1833, "en un congreso que representaba a los sindicalistas y a los cooperativistas, lanzar una amplia organización», cuyo objetivo era doble: "por una parte, coordinar las coaliciones locales, en particular para las huelgas y

35 MARTíNEZ CHARTERINA, Alejandro. La cooperativa y su identidad. Editorial Dykinson S.L., Madrid, 2016, págs. 45-47.

36 HOLYOAKE, Georges Jacob. Historia de los Pioneros de Rochdale. Op. cit., pág. 34.

37 Ibidem. 
aumentos salariales; $y$, por otra, reemplazar el régimen de mercado por una economía socialista basada en la cooperación» ${ }^{38}$.

Así, según palabras de RAMA FACAL ${ }^{39}$, «en 1834 se funda la Gran Unión Industrial Consolidada de Gran Bretaña e Irlanda, especie de sindicato único con 800.000 afiliados, que procuraba la solidaridad recíproca entre sus asociados, y «el derrumbamiento de la economía capitalista en conjunto, a fin de sustituirla por la cooperación del trabajo entre todos los productores»». Uno de cuyos dirigentes, «publica por entonces un folleto en el cual se considera por primera vez la idea de la huelga general y su importancia para la clase trabajadora».

La experiencia cooperativista de esos años, sería referida más tarde en el Manifiesto inaugural de la Asociación Internacional de los Trabajadores, la conocida como I Internacional, fundada por representantes de diversas organizaciones y asociaciones del movimiento obrero; manifiesto que fue redactado por MARX40 en 1864:

Nos referimos al movimiento cooperativo, y, sobre todo, a las fábricas cooperativas creadas, sin apoyo alguno, por la iniciativa de algunas «manos» [«hands», también significa «obreros»] audaces. Es imposible exagerar la importancia de estos grandes experimentos sociales que han mostrado con hechos, no con simples argumentos, que la producción en gran escala y al nivel de las exigencias de la ciencia moderna, puede prescindir de la clase de los patronos, que utiliza el trabajo de la clase de las «manos»; han mostrado también que no es necesario a la producción que los instrumentos de trabajo estén monopolizados como instrumentos de dominación y de explotación contra el trabajador mismo; y han mostrado, por fin, que lo mismo que el trabajo esclavo, lo mismo que el trabajo siervo, el trabajo asalariado no es sino una forma transitoria inferior, destinada a desaparecer ante el trabajo asociado que cumple su tarea con gusto, entusiasmo y alegría. Robert Owen fue quien sembró en Inglaterra las semillas del sistema cooperativo; los experimentos realizados por los obreros en el continente no fueron de hecho más que las consecuencias prácticas de las teorías, no descubiertas, sino proclamadas en voz alta en 1848.

38 DROZ, Jacques (director). Historia general del socialismo. De los orígenes a 1875. Op. cit., págs. 432-434.

39 RAMA FACAL, Carlos Manuel. Las ideas socialistas en el siglo XIX. Ediciones Iguazu, Buenos Aires, 1966, pág. 69.

40 MARX, Karl. «Manifiesto inaugural de la Asociación Internacional de los trabajadores». En Obras escogidas, Editorial Progreso, Moscú, 1979, Tomo II, pág. 11. 
Al mismo tiempo, proseguía el manifiesto, la experiencia cooperativista de los años 1848 a 1864 había probado que, por excelente que fuera en principio y por útil que se mostrara en la práctica, el trabajo cooperativo, "limitado estrechamente a los esfuerzos accidentales y particulares de los obreros», no podría detener jamás «el crecimiento en progresión geométrica del monopolio, ni emancipar a las masas, ni aliviar siquiera un poco la carga de sus miserias». De manera que, para «emancipar a las masas trabajadoras», la cooperación debía alcanzar «un desarrollo nacional y, por consecuencia, ser fomentada por medios nacionales» ${ }^{41}$.

Posteriormente, en el I Congreso de la Internacional, celebrado en Ginebra del 3 al 8 de septiembre de 1866, sería aprobada, entre otras, una resolución en relación al «trabajo cooperativo». Con ella, la asociación se proponía «unir los movimientos espontáneos de la clase obrera, pero, de ninguna manera, dictarle o imponerle cualquier sistema doctrinario». Motivo por el cual, el Congreso se negó a proclamar uno u otro sistema especial de cooperación, limitándose a la enunciación de algunos principios generales ${ }^{42}$.

El Congreso señaló que el movimiento cooperativo «es una de las fuerzas transformadoras de la sociedad presente, basada en el antagonismo de clases». Y destacó que, el gran mérito de este movimiento, consistía en haber mostrado cómo «el sistema actual de subordinación del trabajo al capital, sistema despótico que lleva al pauperismo, puede ser sustituido con un sistema republicano y bienhechor de asociación de productores libres e iguales». No obstante, insistió en que el movimiento cooperativo, limitado a las formas aisladas, jamás podría «transformar la sociedad capitalista». Por lo que, a fin de "convertir la producción social en un sistema armónico y vasto de trabajo cooperativo», consideraba indispensable llevar a cabo cambios sociales generales, cambios de las condiciones generales de la sociedad, los cuales, añadía, sólo podrían lograrse «mediante el paso de las fuerzas organizadas de la sociedad, es decir, del poder político, de manos de los capitalistas y propietarios de tierras a manos de los productores mismos» ${ }^{43}$.

La resolución adoptada, aconsejaba a «los obreros que se ocupen preferentemente de la producción cooperativa, y no del comercio cooperativo».

41 Ibidem, 12.

42 MARX, Karl. «Instrucción a los delegados del Consejo Central Provisional». En Obras escogidas, Editorial Progreso, Moscú, 1979, Tomo II, págs. 82 y 468.

43 Ibidem. 
Pues, este último, no afectaba más que a la superficie del actual sistema económico, «mientras que la primera socavaba sus cimientos». Y recomendaba que, "para evitar la degeneración de las sociedades cooperativas en simples sociedades burguesas por acciones», los obreros y obreras de cada empresa, «independientemente de si están asociadas o no», debían "cobrar igual parte de los ingresos» ${ }^{44}$.

Por último, se hacía una referencia expresa a la asignación de parte de los ingresos comunes a un fondo de promoción cooperativa para la creación de nuevas cooperativas de producción:

Recomendamos a todas las sociedades cooperativas que conviertan una parte de sus ingresos comunes en fondo de propaganda de sus principios, tanto con el ejemplo, como con la palabra, a saber, contribuyendo al establecimiento de nuevas sociedades cooperativas de producción, a la par con la difusión de su doctrina ${ }^{45}$.

\title{
Conclusiones
}

Como es sabido, el primer objetivo del Fondo de Reserva Obligatorio es la autofinanciación de la sociedad cooperativa. No obstante, dicho fondo también está garantizando su ampliación y la propia extensión del sistema cooperativo. Lo que permite incorporar cada vez más personas (principio de «libre adhesión» o «puerta abierta»), al tiempo que se cumple con la aspiración de cooperativizar la organización económica y social de todo el trabajo, pretensión que compartían tanto los «Pioneros de Rochdale» como quienes fundaron la I Internacional.

De igual modo, el Fondo de Educación y Promoción, vinculado a los principios cooperativos de «promoción de la educación» y «compromiso social», está destinado a la formación y educación de las personas asociadas y trabajadoras en los principios y valores cooperativos, o en materias especificas de su actividad societaria o laboral y demás actividades cooperativas; a la difusión del cooperativismo; a la promoción de las relaciones intercooperativas y otras actividades en beneficio del entorno local o de la comunidad en general; así como a acciones de protección medioambiental. Lo que LASSERRE46 Ilamó el "sector social» del cooperativismo y destacó como particularmente desarrollado en las cooperativas de reclutamiento obrero e inspiración socialista.

\author{
44 Ibidem. \\ 45 Ibidem. \\ 46 LASSERRE, George. El cooperativismo. Op. cit., págs. 21 y 22.
}


Algo que, por otro lado, quedó patente en el VIII Congreso de la II Internacional socialista, celebrado en Copenhague en 1910, el cual subrayó la importancia del movimiento cooperativo y de su relación con las organizaciones políticas y sindicales de aspiración socialista. Aquel mismo año, el Congreso de Hamburgo de la Alianza Cooperativa Internacional $(\mathrm{ACl})$, recibiría con satisfacción las resoluciones tomadas en Copenhage por la II Internacional. Dentro de las cuales, se recogía una mención expresa a la utilización de los excedentes cooperativos, así como a su función educativa y solidaria:

Considerando, que las Sociedades Cooperativas de consumo no sólo procuran ventajas materiales inmediatas a sus afiliados, sino que tienen por objetivo: 1. ${ }^{\circ}$ Aumentar la potencia del proletariado, por la supresión de intermediarios y por la creación de servicios de producción dependientes de los consumidores organizados, $2 .^{\circ}$ Mejorar las condiciones de vida obrera, $3 .^{\circ}$ Educar a los trabajadores mediante la administración con plena independencia de sus propios negocios, y ayudares de este modo a preparar la democratización y la socialización de las fuerzas de producción y de cambio.

Considerando que la cooperación por sí sola sería impotente para realizar el objetivo que persigue el Socialismo que es la conquista de los poderes públicos mediante la apropiación colectiva de los medios de trabajo.

El Congreso, poniendo en guardia a los trabajadores contra los que sostienen que la Cooperación se basta a sí misma, declara que la clase obrera tiene el mayor interés en utilizar en su lucha de clases, el arma cooperativa, y exige que todos los socialistas y obreros sindicados participen activamente en el Movimiento Cooperativo, a fin de desarrollar dentro del mismo el espíritu del Socialismo e impedir que las cooperativas se aparten del papel de educación y de solidaridad obrera.

Los cooperadores socialistas tienen el deber de luchar:

1. Porque los excedentes no se devuelvan íntegramente a los afiliados, sino que una parte de ellos se destinen, bien por las propias Cooperativas, bien por las Federaciones o Almacenes al por mayor, al sostenimiento de los afiliados, al desarrollo de la producción cooperativa y a fines de educación y enseñanza.

2. Porque las condiciones de salario y de trabajo en las Cooperativas se resuelvan de acuerdo con los Sindicatos.

3. Porque la organización del trabajo en las Cooperativas sea ejemplar y que la adquisición de mercancías se efectúe por ellas teniendo en cuenta las condiciones de trabajo de los que las han producido. 
Pertenece a las diversas Cooperativas en cada país el decidir si deben ayudar directamente y en qué medida con sus propios recursos al movimiento político y sindical. Teniendo en cuenta que los servicios que la Cooperación puede prestar, serán tanto mayores cuanto el movimiento cooperativo sea más fuerte y más unido, el Congreso declara que las Cooperativas de cada país, que estén constituidas sobre la base de la presente resolución, deben formar una sola Federación.

Y declara que la clase obrera, en su lucha contra el capitalismo, tiene el mayor interés en que los sindicatos, las Cooperativas y el Partido Socialista, aun conservando su autonomía y su unidad propias, estén unidos por relaciones cada día más íntimas ${ }^{47}$.

No debe de sorprendernos por ello, que ya en 1844 «los campesinos pobres del pueblo danés de Rodding» crearan «escuelas cooperativas de nivel secundario», como destaca GIL DE SAN VICENTE ${ }^{48}$. O que en el año 1893, las cooperativas británicas ayudaran «con alrededor de 35.000 libras esterlinas a los centros culturales obreros, y a muchas huelgas de trabajadores». Ya que, al igual que concluye el autor, resultaba lógico e inevitable que el movimiento obrero generase sus propios instrumentos de lucha y formas de resistencia.

Lo que conecta, como ya hemos visto, los fondos sociales obligatorios y su irrepartibilidad, con la génesis del cooperativismo moderno y del resto del asociacionismo obrero.

\section{Fuentes documentales}

\section{Bibliografía}

ALONSO PÉREZ, Matilde. «El cooperativismo valenciano: Desde sus inicios hasta la Ley de 1974». CIRIEC-España, n. 11, 1991, págs. 53-68.

ARRIETA, Leyre; BARANDIARAN, Miren; MUJIKA, Alazne y RODRÍGUEZ, José Antonio. El Movimiento Cooperativo en Euskadi 1884-1936. Fundación Sabino Arana Kultur Elkargoa, Bilbao, 1998.

CHAVES ÁVILA, Rafael. "Las cooperativas en la Segunda República Española. 1931, primera Ley Española de Cooperativa». Noticias del CIDEC, n. ${ }^{\circ} 33$, 2001, págs. 82-85.

47 ARRIETA, Leyre; BARANDIARAN, Miren; MUJIKA, Alazne y RODRIGUEZ, José Antonio. El Movimiento Cooperativo en Euskadi 1884-1936. Op. cit., págs. 92-94.

48 GIL DE SAN VICENTE, Iñaki. Cooperativismo obrero, consejismo y autogestión socialista. Op. cit., págs. 27, 48 y 49. 
COLE, George Douglas Howard. A century of cooperation. The Cooperative Union Limited, Londres.

CRAWFORD, John. "The community library in Scottish history». IFLA Journal, vol. 28, n. ${ }^{\circ}$ 5-6, 2002, pág. 1-13.

DROZ, Jacques (director). Historia general del socialismo. De los orígenes a 1875. Ediciones Destino S.A., Barcelona, 1984, Tomo II.

ELENA DÍAZ, Fernando. "El Fondo de Reserva obligatorio en la nueva Ley General de Cooperativas». REVESCO Revista de Estudios Cooperativos, n. ${ }^{\circ}$ 56-57, 1988-1989, pág. 49-82.

ENGELS, Friedrich. La situación de la clase obrera en Inglaterra. Akal Editor, Madrid, 1976.

FOTHERGILL ROBINSON, Margaret. The Spirit of Association, being some account of the gilds, friendly societies, co-operative movement, and trade unions of Great Britain. John Murray, Londres, 1913.

GIL DE SAN VICENTE, Iñaki. Cooperativismo obrero, consejismo y autogestión socialista. Algunas lecciones para Euskal Herria. Boltxe Liburuak, Bilbao, 2013.

HOLYOAKE, Georges Jacob. Historia de los Pioneros de Rochdale. Intercoop Editora Cooperativa Ltda, Buenos Aires, 1989.

KOLMERTEN, Carol A. Women in Utopia: The Ideology of Gender in the American Owenite Communities. Syracuse University Press, Nueva York, 1998.

LAMBERT, Paul. La doctrina cooperativa. Intercoop Editora Cooperativa Limitada, Buenos Aires, 1970.

LASSERRE, George. El cooperativismo. Oikos-tau S.A., Barcelona, 1972.

LICHTHEIM, George. Breve historia del socialismo. Alianza Editorial, Madrid, 1970.

MARTÍNEZ CHARTERINA, Alejandro. La cooperativa y su identidad. Editorial Dykinson S.L., Madrid, 2016.

MARX, Karl. «Manifiesto inaugural de la Asociación Internacional de los trabajadores». En Obras escogidas, Editorial Progreso, Moscú, 1979, Tomo II, pág. 5-13.

MARX, Karl. «Instrucción a los delegados del Consejo Central Provisional». En Obras escogidas, Editorial Progreso, Moscú, 1979, Tomo II, págs. 77-86.

MAYO, Ed. Breve historia de la cooperación y la mutualidad. Co-operatives UK, Manchester, 2017.

MCDONNELL, Diarmuid; MACKNIGHT, Elisabeth y DONNELLY, Hugh. "Case Study 1.4. The Fenwick Weavers». Reseña de The Co-operators - A History of the Fenwick Weavers, de John McFadzean. En Democratic Enterprise: Ethical business for the 21st century. Co-operative Education Trust Scotland, Escocia, 2012.

MERINO HERNÁNDEZ, Santiago. "Los orígenes del cooperativismo moderno y el socialismo premarxista». GEZKI, n. ${ }^{\circ} 1,2005$, pág. 169-188.

MORALES GUTIÉRREZ, Alfonso Carlos. "La democracia industrial en España: orígenes y desarrollo de las empresas de trabajo asociado en el siglo XX». CIRIEC-España, Revista de Economía Pública, Social y Cooperativa, n. ${ }^{\circ} 44$, 2003, pág. 137-173. 
RAMA FACAL, Carlos Manuel. Las ideas socialistas en el siglo XIX. Ediciones Iguazu, Buenos Aires, 1966.

THOMPSON, Edward Palmer. La formación de la clase obrera en Inglaterra. Capitán Swing, Madrid, 2012.

\section{Normativa}

DECRETO de 4 de julio de 1931, determinando lo que ha de entenderse por Sociedad Cooperativa y fijando sus condiciones legales, publicado en la Gaceta de Madrid, n. ${ }^{\circ}$ 188, de 7 de julio de 1931.

LEY de 9 de septiembre de 1931, declarando Leyes de la República los Decretos que se insertan, publicada en la Gaceta de Madrid, n. ${ }^{\circ}$ 253, de 10 de septiembre de 1931.

DECRETO de 2 de octubre de 1931, aprobando el Reglamento para la aplicación de la ley de Cooperativas, publicado en la Gaceta de Madrid, n. ${ }^{\circ} 294$, de 21 de octubre de 1931.

LEY de 2 de enero de 1942, de cooperación, publicada en el Boletín Oficial del Estado, n. ${ }^{\circ} 12$, de 12 de enero de 1942.

DECRETO de 11 de noviembre de 1943, aprobando el Reglamento para la ejecución de la Ley de Cooperativas de 2 de enero de 1942, publicado en el Boletín Oficial del Estado, n. ${ }^{\circ}$ 55, de 24 de febrero de 1944.

ORDEN de 10 de marzo de 1944, por la que se dispone se publiquen nuevamente en el Boletín Oficial del Estado los artículos del Reglamento para la aplicación de la Ley de Cooperación, inserto en dicho Boletín de 24 de febrero último, debidamente rectificados, publicada en el Boletín Oficial del Estado, n. ${ }^{\circ} 76$, de 16 de marzo de 1944.

LEY 3/1987, de 2 de abril, General de Cooperativas, publicada en el Boletín Oficial del Estado, n. ${ }^{\circ} 84$, de 8 de abril de 1987. 


\section{Derechos de autor}

El Boletín de la Asociación Internacional de Derecho Cooperativo es una revista de acceso abierto lo que significa que es de libre acceso en su integridad inmediatamente después de la publicación de cada número. Se permite su lectura, la búsqueda, descarga, distribución y reutilización legal en cualquier tipo de soporte sólo para fines no comerciales y según lo previsto por la ley; sin la previa autorización de la Editorial (Universidad de Deusto) o el autor, siempre que la obra original sea debidamente citada (número, año, páginas y DOI si procede) y cualquier cambio en el original esté claramente indicado.

\section{Copyright}

The International Association of Cooperative Law Journal is an Open Access journal which means that it is free for full and immediate access, reading, search, download, distribution, and lawful reuse in any medium only for non-commercial purposes, without prior permission from the Publisher or the author; provided the original work is properly cited and any changes to the original are clearly indicated. 